\title{
Rearticulando narrativas sociológicas: teoria social brasileira, diáspora africana e a desracialização da experiência negra
}

\section{Priscila Martins Medeiros*}

Resumo: Neste artigo apresento resultados da pesquisa "A sociologia brasileira e os estudos diaspóricos", na qual analiso algumas abordagens da sociologia brasileira no tema das relações étnico-raciais e seus pontos de convergência com o debate transnacional sobre a diáspora africana e a crítica pós-colonial. O objetivo central deste artigo é, através da seleção de alguns textos brasileiros, compreender as proximidades entre o pensamento social brasileiro e a crítica pós-colonial e em que medida essa relação nos permite revisitar o que ficou conhecido como "sociologia das relações raciais" no Brasil. $\mathrm{O}$ artigo se estrutura através de dois aspectos gerais, quais sejam: $a$. as diferentes compreensões, por parte de alguns autores da sociologia brasileira, sobre a modernidade e o ethos nacional, e como que a crítica pós-colonial tensiona as bases gerais de compreensão da sociedade brasileira; $b$. a revisão das noções clássicas de resistência e política, através da estética e das expressões culturais da diáspora. Do nosso ponto de vista, esses aspectos nos ajudam a compreender os processos históricos que racializaram a experiência negra no Brasil, e nos apontam alguns limites analíticos de parte da interpretação sociológica brasileira sobre nossa formação social.

Palavras-chave: Sociologia brasileira. Estudos pós-coloniais. Diáspora africana. Modernidade. Ethos nacional.

\section{Rearticulating sociological narratives: \\ Brazilian social theory, African diaspora and disracialization of the black experience}

\begin{abstract}
In this article I present results of the research "Brazilian sociology and diasporic studies", in which I analyze some approaches of Brazilian sociology in the theme of ethnic-racial relations and their points of convergence with the transnational debate on the African diaspora and postcolonial criticism. The central objective of this article is to understand the proximity between Brazilian social thought and postcolonial criticism through the selection of some Brazilian texts and to what extent this relationship allows us to revisit what has become known as "Sociology of race relations" in the Brazil. The article is structured through two general aspects, namely: a. the different understandings by some authors of Brazilian sociology on modernity and the national ethos, and how postcolonial criticism stresses the general bases of understanding of the Brazilian society; $b$. the revision of the classical notions of resistance and politics, through the aesthetics and cultural expressions of the diaspora. From our point of view, these aspects help us to understand the historical processes that racialized the black experience in Brazil, and point out some analytical limits on the part of Brazilian sociological interpretation of our social formation.
\end{abstract}

Key Words: Brazilian sociology. Postcolonial studies. African diaspora. Modernity. Ethos national.
* Priscila Martins Medeiros é doutora em sociologia pela Universidade Federal de São Carlos (UFSCar), mestre em sociologia e bacharel em ciências sociais, ambos pela UFSCar. É professora adjunta do Departamento de Sociologia da Universidade Federal de São Carlos, São Paulo, Brasil. $<$ medeiros.ufscar@ gmail.com> 


\section{Introdução}

D esde 2016 tenho realizado uma pesquisa na qual analiso as proximidades temáticas e conceituais entre a sociologia brasileira e a crítica pós-colonial e contempla essa relação que permite revisitar o que ficou conhecido como "sociologia das relações raciais" no Brasil. Também selecionei os trabalhos de alguns outros autores que não estão inseridos diretamente no campo da sociologia, mas que contribuem em outras áreas formadoras das chamadas ciências sociais.

É importante destacar que neste texto não tenho a intenção de caracterizar qualquer autor da sociologia brasileira enquanto representante do pensamento pós-coIonial. Uma afirmação como essa seria, primeiramente, uma comparação forçosa e, em segundo lugar, não vejo necessidade disso. O que me interessa de fato é perceber em que medida alguns dos argumentos de renomados pensadores brasileiros - em diferentes intensidades - constitui uma importante linha de análise sobre os processos de racialização presentes na história do país. Temas como: a especificidade da experiência social do negro no Brasil; as diferentes formas de resistência e de atuação dessa população, seja através da atuação política "direta" ou de outras formas também políticas, como pela afirmação estética ou do corpo; ou ainda o dilema das narrativas de nação "sem povo", na medida em que não questionam o local social de abjeto do negro no país, são alguns dos assuntos fomentados por autores brasileiros que, em alguma medida, se aproximam de críticas como as realizadas pelos estudos pós-coloniais. O que a pesquisa nos permite afirmar, portanto, são pontos de contato entre agendas teóricas, e não a inclusão de autores brasileiros naquilo que chamamos de estudos pós-coloniais.

Quando se fala em racialização faz-se referência aos processos históricos e sociais que estabelecem significados a determinados indivíduos e grupos. O que ocorre é uma biologização de ideologias racistas, cristalizando-as no corpo e na história dessas pessoas e transformando-as em "verdades" corporificadas. Esses processos ocorrem no interior das instituições, nas interações cotidianas, nas ações e nos silêncios. E, ao criarem "verdades", são estabelecidos os respectivos "lugares sociais" para os grupos atingidos por esses processos; são criadas também as expectativas coletivas sobre como esses grupos devem agir, pensar e ser, ou melhor, nascem aí os "sujeitos típicos" para tais ideologias.

O que justifica o esforço em se buscar os pontos de contato entre a sociologia brasileira e os estudos pós-coloniais? Ao reexaminar alguns dos grandes trabalhos da sociologia brasileira, que abordaram o tema da escravidão e do racismo, percebe-se que a interpretação das relações sociais no Brasil se deu primordialmente para den- 
tro dos limites "do nacional". Um exemplo disso é que as questões raciais no Brasil não foram discutidas tendo como base a compreensão sobre os grupos africanos sequestrados para o Brasil, formadores da nossa história social. Ao invés disso, nossa sociologia se debruçou em torno de uma criação nacional: o "negro". O negro, enquanto categoria, é uma espécie de filtro das diferenças étnicas, unificando-as em torno de um "novo sujeito". E aqui utilizo o termo "novo sujeito" entre aspas para destacar seu significado limitado, pois ele nasce ao mesmo tempo em que um lugar social específico é para ele estabelecido: um lugar de não existência ou, nas palavras de Frantz Fanon, uma "zona de são ser" (Fanon, 2008: 26). Se é um novo sujeito, seu passado é nebuloso, pouco compreensível e "borrado" aos nossos olhos. E então, os descendentes de africanos no Brasil são retratados sociologicamente em dois momentos: o escravo e o negro. A primeira transformação simbólica é a do Bantu (por exemplo) em africano, genericamente. Em seguida, o africano passa a significar escravo. Por último, o escravo torna-se negro, uma categoria que constrange toda uma população a uma nova condição simbólica, desconectada de sua história com o continente africano. Cabe salientar que a demanda por uma história brasileira conectada com a África não significa um movimento essencialista ou de retorno a uma África mítica a-histórica. Significa, isso sim, uma leitura da realidade brasileira que leve em consideração as dinâmicas sociais que a conformam, no passado e no presente.

Esse processo de unificação das diferenças em torno de uma categoria nacional é um exemplo de racialização, que criou os significados do "ser negro", assim como o do "ser branco" e do "ser indígena" em nossa sociedade. Trata-se de uma produção discursiva, com impactos sobre as subjetividades e em como compreendemos e narramos nosso contexto social. Para compreendermos a complexidade de nossa sociedade e dos significados compartilhados, é necessário nos atentarmos aos processos de racialização. Mais do que isso, precisamos de leituras transnacionais - ou "supranacionais", nas palavras de Joel Rufino dos Santos (1985: 301) - que ultrapassem as fronteiras do nacional e que, portanto, não se limitem às categorias que ignoram a presença da África em nossa história. Essa limitação é, no entanto, marcante na sociologia brasileira. O que pretendo neste trabalho é justamente mapear os momentos em que os sociólogos se desconectam dessa limitação analítica e se aproximam daquilo que os autores pós-coloniais realizam: a crítica ao processo colonial e aos resultados práticos, simbólicos e subjetivos da racialização que é inerente a tudo isso e reproduzido diariamente.

Logo ao iniciar os trabalhos de pesquisa, percebi que a compreensão das transformações teórico-conceituais na sociologia brasileira, com foco no tema étnico-racial, depende de pelo menos dois aspectos, quais sejam: 
a. O debate em torno do ethos nacional, da modernidade e dos códigos culturais presentes no país. As avaliações dos autores variam desde a compreensão de um ethos marcado negativamente pela cordialidade, até as leituras sobre um códice africano que emoldura nosso ser brasileiro.

b. A possibilidade de revisão das noções clássicas de resistência e política, através da estética e das expressões culturais da diáspora, demonstrando as relações entre cultura e política, para além das formas clássicas ou burocráticas do "fazer político".

A modernidade e o progresso como projetos para o país, bem como os dilemas e os desafios para sua consolidação, são temas que atravessam toda a nossa literatura sociológica. E as diferentes compreensões sobre a "modernidade" (periférica, seletiva, revolução passiva, modernidade negra, entre outras leituras) nos trazem resultados muito díspares quanto à interpretação de nossas relações raciais e do processo de diáspora. A diáspora, mais do que um marco histórico iniciado pela dispersão forçada de africanos pelo mundo, significa a formação de rotas culturais criadas pela presença de africanos e de seus descendentes por todos os continentes, que originaram um circuito de expressões culturais, estruturas de sentimento, formas de sociabilidade e lugares de memória, hibridizadas e constantemente transformadas (Gilroy, 2001; Hall, 2006; Horowitz, 2005).

Ethos e modernidade:

da conciliação freyriana aos

códigos culturais da diáspora africana

Para atender aos meus objetivos, busco as articulações existentes entre os autores de nossa sociologia que nos auxiliem, primeiramente, a captar seus argumentos de base sobre a modernidade brasileira. Nesse sentido, é possível percebermos uma tendência comum entre dois dos maiores sociólogos brasileiros: tanto para Gilberto Freyre quanto para Sérgio Buarque de Holanda, o desenvolvimento do ethos brasileiro reside mais em comportamentos emocionais do que em arranjos racionais.

Gilberto Freyre localizou na questão racial um componente fundamental para se pensar a nação, explicada através do equilíbrio de antagonismos. Para o autor, a chave interpretativa sobre o desenvolvimento do ethos brasileiro reside justamente no equilíbrio entre os complexos Casa-Grande \& Senzala; Sobrados e Mucambos; 
Ordem \& Progresso. Esses complexos seriam marcados por elementos nem sempre racionais de comportamento, como também não ortodoxos.

Gilberto Freyre, em 1933, informou-nos que seríamos, desde o início, uma sociedade híbrida. Híbrida - de acordo com Freyre - significava que o Brasil, entre todas as sociedades da América, seria aquela que se

[...] constituiu mais harmoniosamente quanto às relações de raça: dentro de um ambiente de quase reciprocidade cultural que resultou no máximo aproveitamento dos valores e experiências dos povos atrasados pelo adiantado; no máximo da contemporização da cultura adventícia com a nativa, da do conquistador com a do conquistado (Freyre, 2006: 91).

A sociedade híbrida, característica considerada por Freyre como o caminho certo e seguro para a modernização do país, é aquela que teria tido a capacidade de operar uma síntese cultural não conflituosa. E é isso que teria permitido a permanência dos códigos sociais com o mínimo de rusgas. As marcas da sociabilidade brasileira seriam, portanto, a acomodação e a conciliação, que são resultados, em parte, da assimilação cultural pelo conjunto da sociedade; de usos, costumes e valores de diferentes referências culturais. Para Freyre, o elemento civilizador brasileiro é o africano que, através da alegria, da bondade dos usos e costumes de higiene e da alimentação, se mostrou o grupo social de maior plasticidade e adaptação entre os demais. Ainda que esse argumento seja absolutamente revolucionário para a época, Gilberto Freyre idealiza a tal ponto as relações entre brancos e negros que as deforma, apagando as tintas da brutal hierarquia racial e da violência.

Um dilema de caráter político-social estava posto no início do século XX: no pós-abolição, e com a presença do imigrante europeu, quais seriam as possibilidades de transformação do escravizado em trabalhador livre, estendendo efetivamente os direitos de cidadania à totalidade da população? Dito de outra forma, qual a viabilidade de um novo projeto social, pautado agora em direitos, na livre associação e no trabalho assalariado? Gilberto Freyre, ao lançar luz sobre a temática racial em outros termos, valorizando o mestiço, transformou o "problema" ou o "obstáculo" à integração nacional, em sua maior força. Freyre, através de uma leitura sofisticada da realidade brasileira, inverteu a chave sobre a miscigenação, tornando-a um dado a ser positivado no país. Na percepção de Élide Rugai Bastos (2006), esse movimento realizado por Freyre teria, para a sua época, equacionado o problema do povo brasileiro em outro patamar, distanciando-nos das concepções pessimistas ou fatalistas sobre as possibilidades de se estabelecer uma nação de fato. A autora salienta, 
no entanto, que, em nome dessa suposta conciliação é que se negou, nas décadas seguintes, os direitos de cidadania à quase totalidade da população brasileira. Dessa maneira, a dominação se reitera pois se reveste de diversidade e esconde a desigualdade.

Leonardo Avritzer e Lilian Gomes (2013) observam que a obra de Freyre, em especial Casa Grande \& Senzala, versa sobre a mestiçagem, a esfera privada e o trânsito cultural brasileiro, praticamente eximindo-se da dominação patriarcal. Ao fazê-lo, Freyre substitui essa dominação por uma espécie de teoria da democracia, que versaria sobre nossa suposta formação democrático-igualitária, privilegiando o ponto de vista da elite agrária brasileira. Para os autores é inegável a existência de forte trânsito entre índios, portugueses e negros na esfera da vida privada. O problema, no entanto, é que, ao assumirmos a linha argumentativa freyriana, podemos supor que a questão racial encontrará sua solução em tais trânsitos propiciados pela esfera privada, supostamente igualitária e democrática, o que é um engano (Avritzer \& Gomes, 2013: 49).

Gilberto Freyre imaginou uma síntese cultural para o Brasil, entendida como a chave para a modernização do país. Entendo, porém, que a sociedade híbrida da explicação freyriana tem pouca semelhança com a noção de um espaço genuinamente heterogêneo e de negociação democrática agonística, ou seja, de um espaço de remodelação constante, sem solução final. Aqui faço uma primeira aproximação da sociologia brasileira com os estudos da diáspora, no caso, apontando uma dessemelhança: a sociedade híbrida só pode ser um espaço democrático se não se fechar em torno de uma identidade conservadora, e se nela for privilegiada a presença e a articulação da différance, nos termos de Jacques Derrida (1982).

De acordo com o Derrida, não é possível a compreensão de qualquer sujeito ou grupo social através de um ponto de vista essencialista ou que busque as suas imanências culturais. Isso porque, ainda de acordo com o autor, nunca há um momento em que o significado esteja completo ou totalizado. Ou seja, as palavras e os signos jamais dão conta de evocar exatamente o que eles significam, sempre adiando ou postergando seu significado, numa cadeia sem fim. Desse ponto de vista, Derrida compreende os sujeitos como absolutamente circunstanciais, enquanto narrativas em constante reconstrução, ou seja, jamais pré-existentes, e sim feitos e compreensíveis através dos discursos e das representações sociais (Derrida, 1982).

Nos termos colocados por Stuart Hall (2006), é essencial que uma sociedade multicultural permaneça um espaço heterogêneo e pluralístico, resistindo ao ímpeto de serem integrados por um processo de equivalência formal, tanto no sentido as- 
similacionista - como dita a concepção liberal de cidadania -, quanto do ponto de vista da radicalização das diferenças no sentido "do certo contra o errado", do "bem contra o mal" (Hall, 2006: 83).

Sérgio Buarque de Holanda buscou analisar o encontro de civilizações no Brasil e as implicações disso tanto nos aspectos culturais como institucionais. Ao destacar a inegável influência ibérica entre nós, Holanda conclui que o ethos nacional brasileiro é fundamentado na cultura do personalismo, o que impediria a solidariedade e as formas de organização horizontais no país: "em terra onde todos são barões, não é possivel acordo coletivo durável" (Holanda, 2007: 32). Ao se utilizar da teoria weberiana sobre a burocracia racional, o autor critica nossa formação patrimonialista e personalista e vê nos aspectos culturais brasileiros uma sensível falta de afinidade com o espírito do capitalismo e com os princípios básicos da modernidade.

Para o Holanda, a marca peculiar da vida brasileira no período colonial foi a convivência de valores como o afeto, a irracionalidade e os traços passionais. Esses valores teriam imperado sobre nossa administração e nossa economia, o que é, de acordo com ele, completamente contrário ao que se espera de uma população em vias de se organizar politicamente. Teríamos, portanto, um ethos muito distante do desejável para a consolidação de nossa modernidade, esta que exige planejamento, racionalidade e capacidade de pensamento abstrato. Nosso ethos personalista e patrimonialista seria marcado por uma motivação individual muito diferente daquele visto em outros países americanos: aqui, a ação individual é compreendida como uma espécie de dom - sorte ou acaso - e não como motivação que leve à solidariedade e à coesão. Antes disso, seríamos uma sociedade fundada em privilégios, e não no esforço. Nosso único princípio político, portanto, não poderia ser a democracia, e sim a obediência cega ao mais forte: um princípio de "mandos e desmandos" próprio de culturas medievais e feudais.

Ainda que as conclusões sejam distintas, tanto Gilberto Freyre quanto Sérgio Buarque de Holanda basearam suas análises na chave da modernização do país, o que acabou sendo uma forte marca da sociologia brasileira realizada ao longo de todo o século XX. Nessa perspectiva, o negro se encaixa de maneira desconfortável, pois não carrega consigo os traços clássicos esperados do sujeito moderno. Os problemas da base epistemológica da modernização estão no centro da argumentação crítica pós-colonial, conforme veremos ao longo deste texto.

Diferentemente de Freyre, que acreditava que o Brasil tinha uma dívida histórica para com a família patriarcal, instituição considerada como a base de nossa sociedade, Holanda a concebe como a principal fonte de nossos erros. A família patriarcal, 
de acordo com o autor, carrega em si o principal elemento civilizacional do Brasil - a herança cultural lusitana, da qual ele não se orgulha - e teria sido nossa maior marca, ficando para segundo plano quaisquer outras contribuições culturais de outros grupos (Holanda, 2007: 40).

Logo, vejo duas leituras sobre a história social brasileira: de um lado, Freyre argumenta que nossas características civilizatórias não precisam ser superadas, pelo contrário, devemos valorizar nossa pretensa facilidade conciliatória e nosso "hibridismo"; de outro lado, Holanda visualiza a necessidade de superarmos nossa herança histórica personalista, processo esse que seria facilitado com a urbanização, que retiraria o peso rural, cedendo lugar à presença de massas populares e a novos protagonistas políticos.

Independentemente das diferenças de leituras, ambos os autores enfatizam a centralidade da chamada "família patriarcal" tanto na consolidação do ethos nacional, quanto na concessão de significado para todas as demais instituições brasileiras. Joel Rufino dos Santos (1985), estudioso do racismo no Brasil e leitor de críticos do processo colonial, descreve a família patriarcal brasileira como um círculo de relações em torno de um núcleo inabalável:

No centro, absoluto, o macho branco; à sua volta, em círculos concêntricos, e pela ordem: seus familiares de sangue, agregados brancos e mestiços e, por último, índios e negros. Como nos sistemas heliocêntricos da astronomia medieval, a estabilidade e a coesão dependiam do girar imutável dessas órbitas fixas (Santos, 1985: 302).

Em um de seus maiores insights sobre o assunto, Joel Rufino nos alerta que o pensamento social brasileiro, ao se fundamentar nessa máxima da família patriarcal, desconsidera o povo, afinal, os negros são, nessa leitura, antes de tudo brasileiros. Eles têm lugar assegurado nessa grande família desde que não ameacem a unidade e o equilíbrio. Portanto, de acordo com o autor, os estudos clássicos da sociologia e das ciências sociais brasileiras, que marcaram grande parte do século XX, acabam por sintetizar a imagem de uma nação sem povo (Santos, 1985: 306).

Mas então, não haveria uma leitura diferente dessa que marcou o pensamento social brasileiro? Na concepção de Joel Rufino sim, se passarmos a considerar as particularidades da experiência negra, incluindo o que toca à família. De acordo com o autor, nas famílias negras, a "tia" ocupa o centro das relações; as agregações são por adoção ou afinidade/necessidades e não por consanguinidade; a família é extensa e aberta, com poucos papéis sociais prévios e fixos (Santos, 1985: 306). 
Essa crítica, ao meu ver, confronta muitos trabalhos clássicos do pensamento social brasileiro que, de maneiras diversas, tomaram a família patriarcal como pressuposto para as suas análises, o que desconsidera, ao fim e ao cabo, o povo. Nisso podemos citar Gilberto Freyre, Sérgio Buarque de Holanda e Maria Sylvia de CarvaIho Franco. Mesmo Florestan Fernandes não chegou a colocar em risco a ideia de família patriarcal como centro explicativo da realidade social brasileira.

Roger Bastide (1974) em sua obra As Américas Negras: as civilizações africanas no Novo Mundo (originalmente publicada em 1967), realiza um interessante debate acerca dos elementos culturais formadores do Brasil, o que o aproxima bastante das preocupações traçadas pelos intelectuais da diáspora africana. Na perspectiva de Bastide, no Brasil haveria características e complexos culturais africanos que teriam sobrevivido frente às relações econômicas e sociais adversas, dando origem a dois tipos de formação, quais sejam: as "comunidades africanas" e as "comunidades negras". Tendo como ponto de partida o estudo clássico de antropologia cultural intitulado The myth of the negro past, de Melville J. Herskovits (1945) ${ }^{1}$, Bastide aprofunda as pesquisas sobre as sobrevivências africanas nas Américas.

No primeiro caso, "os modelos africanos levam vantagem sobre a pressão do meio ambiente" (Bastide, 1974: 44), permanecendo como preponderantes na organização social, na vida econômica, nas instituições, nas tecnologias, na linguagem, na religião, na arte e no folclore. No segundo caso, as "comunidades negras" seriam formas de sociabilidade, com base em tipos de associativismo, nas quais os negros tiveram que inventar formas de conduzir a vida, sem referências explícitas às suas culturas de origem, ainda que tenham conservado características africanas. As sociedades do segundo tipo (negras) são "verdadeiras criações culturais originais, respondendo às novas circunstâncias de vida" (Bastide, 1974: 29) criadas como forma de reação ao contexto opressor da colônia, à imposição do cristianismo e à violenta mudança territorial que a escravidão impôs².

De acordo com Bastide, o "antigo" só pode reviver adaptando-se às novas condições de existência, e isso não significa uma ruptura com traços culturais africanos. Pelo contrário, a adaptação "é o símbolo mais tocante da fidelidade" (Bastide, 1974: 40). A sobrevivência de aspectos culturais pressupõe necessariamente a plasticidade. No contato entre diferentes referências culturais, o processo de adaptação é seletivo, ou seja,

empresta-se a outrem, ou então o que pode combinar com as normas ancestrais, o que se banha em um mesmo clima geral, místico ou de festa, ou ainda o que permite uma melhor adaptação, o que é útil (Bastide, 1974: 179).
1. Herskovits desenvolveu o conceito de "retenções" que, para alguns críticos, corresponde à noção de "raízes" culturais, mais estáticas do que dinâmicas. Essa leitura é bastante diferente da perspectiva empregada pelos teóricos póscoloniais, que abordam as "rotas" e as complexas transformações históricas. É também nesse sentido de movimento e processo histórico que o termo "rizoma" é desenvolvido por Deleuze e Guattari (Mintz \& Price, 2003). É interessante notar que a obra de Roger Bastide, inspirada em Herskovits, foi capaz de diluir os essencialismos e de promover a análise da experiência negra nas Américas de um ponto de vista radicalmente histórico e contextual.

2. Roger Bastide traz interessantes descrições sobre as famílias negras, a transmissão, por parte das mulheres mais velhas, da língua falada e também das adaptações que os adeptos das religiões dos orixás (Candomblés Nagô na Bahia, Xangô em Pernambuco e Alagoas e do Batuque do Rio Grande do Sul) precisaram realizar no Brasil, como forma de resistência. 
Foi assim com as adaptações religiosas, com o calendário das festas religiosas, com a língua, a culinária entre outros aspectos.

O que essa perspectiva de Roger Bastide nos apresenta? Ele elenca aspectos da sociabilidade brasileira que estão subsumidos nas literaturas de Gilberto Freyre, Sérgio Buarque de Holanda, entre outros aqui já citados. Ainda que Freyre tenha feito o elogio aos elementos culturais africanos, como marcas da nossa civilização, os mesmos perdem esse status para a "morenidade". Já na literatura de Holanda, as contribuições culturais africanas seriam secundárias, na medida em que, de acordo com o autor, a herança ibérica seria nossa grande marca cultural. Afina como já citamos através de Joel Rufino dos Santos -, temos um povo marcado por outras formas de sociabilidade, como, por exemplo, com a importância conferida às "tias" nas comunidades negras.

Clóvis Moura (1983), intelectual pouco lido nos cursos de ciências sociais, já havia salientado a característica associativa do negro no Brasil como forma de resistência ao processo de marginalização. O negro sempre se manteve organizado, seja em quilombos, irmandades, confrarias, em grupos religiosos como o candomblé, associações recreativas e artísticas, entre outros. Em Américas Negras, Bastide também salienta essa característica, focando sua análise nos terreiros de candomblé espalhados pelo país. De acordo com o autor, mais do que agrupamentos religiosos, esses espaços também têm a função de aproximar pessoas que sofrem discriminações diversas e que têm necessidades não atendidas pelo governo. Logo, os terreiros têm funções úteis e de solidariedade, por serem espaços de encontro longe da vigilância policial; de proteção à integridade física; de auxílio em assuntos cotidianos e ainda por serem lugares onde as pessoas se sintam reconhecidas em sua dignidade, pois oferecem "um meio de segurança contra os golpes da vida [...] um status de prestígio que não podem esperar alcançar na sociedade global" (Bastide, 1974: 117-118).

Logo, Bastide teve o cuidado de salientar que não se pode negar os aspectos social, político e econômico relacionados à religiosidade em geral e, no caso específico, na de matriz africana. Ao discutir a "dupla diáspora" (Bastide, 1974: 15), marcada pela presença simultânea de comunidades africanas e de comunidades negras nas Américas, Bastide demonstrou que as sobrevivências culturais de origem africana que, à princípio, parecem mais evidentes no universo místico da religião, estão, através da própria religião, pulverizadas em várias esferas da vida social.

Rita Segato (1998), em seu trabalho intitulado "The color-blind subject of myth; or, where to find Africa in the nation", realiza uma discussão próxima ao debate 
proposto por Bastide, ao descrever o que ela chama de "códice africano". O códice é um conjunto de premissas de sociabilidade e de formas de organização social de referência africana que se mantém estáveis dentro da nação e que nos permite falar sobre uma etnicidade africana que marca nosso modo de vida (Segato, 1998: 143). A diferença nas argumentações de Bastide e Segato é que, enquanto o primeiro realiza uma análise que nega a nação enquanto base explicativa do Brasil, Segato, por sua vez, percebe fortes características socioculturais e organizacionais de origem africana que se encaixam dentro da lógica simbólica da nação. As leituras diaspóricas de ambos os autores, portanto, guardam diferenças entre si, ainda que as duas signifiquem um desvio na lógica clássica de explicação da sociabilidade brasileira.

O reconhecimento da existência, no Brasil e nas Américas, de um códice africano aproxima-se do debate proposto por Joel Rufino, quando ele nos alerta sobre as particularidades das famílias negras no Brasil, que são orientadas por outras lógicas de sociabilidade que não aquelas destacadas nas descrições sobre a família patriarcal. O debate sobre códice também nos aproxima de Paul Gilroy (2001) que, alçando o Atlântico Negro como metáfora da experiência diaspórica dos negros, demonstra como que os africanos escravizados recriaram práticas culturais de origem africana de uma maneira bastante original. O autor explica esse processo a partir do conceito de rizoma ${ }^{3}$, emprestado e adaptado do pós-estruturalismo de Deleuze e Guattari, e que, neste caso, significa um conjunto de sistemas culturais que se espalham como rotas nos contextos coloniais, funcionando como novas formas de resistência. A tese central de Gilroy é que a escravidão colonial e a diáspora africana são elementos viscerais da modernidade, suas constituintes, e não fenômenos que tenham ocorrido às suas margens. Portanto, podemos dizer que não haveria uma modernidade negra, mas sim uma modernidade, ponto. Com todas as crises, todos os antagonismos e as desumanidades inerentes a ela (Gilroy, 2001: 103-109).

\section{Cultura e política}

nas rotas da diáspora africana

Paul Gilroy salienta que, no contexto da plantation, uma instituição tipicamente moderna, há perdas, silenciamentos e desumanização. Há também, apesar disso e por isso, o surgimento de elementos novos, de resistência. Se no contexto colonial e escravocrata não são permitidos aos negros a participação política, econômica, nem mesmo o reconhecimento jurídico de sua humanidade, é na estética, na corporeidade e no ritmo que são dadas as possibilidades de ação e de resistência. O autor chama esse processo de "política da transfiguração":
3. Rizoma, no modelo analítico pósestruturalista, é a figura metafórica de "hastes e filamentos que parecem raízes, ou, melhor ainda, que se conectam com elas penetrando no tronco, podendo fazê-las servir a novos e estranhos usos" (Deleuze \& Guattari, 1995: 25). 
Essa política enfatiza o surgimento de desejos, relações sociais e modos de associação qualitativamente novos no âmbito da comunidade racial de interpretação e resistência e também entre esse grupo e seus opressores do passado. Ela aponta especificamente para a formação de uma comunidade de necessidades e solidariedade, que é magicamente tornada audível na música em si e palpável nas relações sociais de sua utilidade e reprodução culturais (Gilroy, 2001: 96).

De acordo com a autora bell hooks (1995), no discurso colonial, o corpo colonizado foi sempre visto como corpo destituído de subjetividade, de voz, vontade e afirmação, estando sempre pronto para servir. Seria, de acordo com a autora, um corpo destituído de alma. E é exatamente por isso que muitos autores, incluindo a própria bell hooks, estabelecem a estética e o corpo como "lugares" contestatórios. O corpo negro é, por si só, um ato político, na medida em que sua existência desestabiliza os discursos predominantes. É o que hooks vem chamar de "aesthetic of blackness" (hooks, 1995: 72).

A reivindicação da experiência negra da estética e da corporeidade como campos políticos, algo que aparece, como vimos, em Gilroy e em hooks, tem raízes teóricas mais profundas, já nos escritos de Du Bois. Logo na abertura do livro The souls of Black Folk, de 1903, Du Bois chama de "estranha experiência" o fato de o negro habitar um corpo cingido pelo discurso colonial, que estabelece a esse sujeito o status de "problema" social. Para o autor, o deslocamento do negro da situação de problema depende, muitas vezes, mais da compreensão das práticas culturais do que do conhecimento profundo das práticas formalmente políticas, que acabam por ofuscar a visão dos observadores. Nesse sentido, The souls of Black Folk é um texto particularmente interessante por trazer um esforço de compreensão das culturas vernaculares que surgiram para mediar os efeitos do terror modernizante. Isso foi essencial para as elaborações posteriores de Paul Gilroy até este chegar ao argumento da política de transfiguração nos contextos marcados pela diáspora africana.

4. Publicado, em conjunto com outros textos, na coletânea Introdução crítica à sociologia brasileira, de 1957.
Que autor do pensamento social brasileiro teria elaborado, ainda em meados do século XX, uma crítica que passa pela compreensão da experiência negra perante o discurso racializante? Podemos dizer que Florestan Fernandes, em A integração do negro na sociedade de classes (1965) passa por esses aspectos ao discutir a criação pela sociedade brasileira de um número sem fim de estereótipos contra a população negra, com o uso da cor (corpo, portanto) como elemento de classificação e de exclusão (Fernandes, 1965, v. 1: 240-341).

Mas, ainda antes da publicação dessa obra de Florestan, Guerreiro Ramos, no texto "O problema do negro na sociologia brasileira" (1957)4, nos apresenta uma discus- 
são muito interessante sobre o que ele chamou de "alienação estética do negro". Para o autor, o cientista social que queira empreender o trabalho de superação definitiva do postulado teórico que coloca o negro como "problema", deve passar pelo procedimento fenomenológico de se praticar "um ato de suspensão da brancura", a fim de se demonstrar a precariedade das concepções racistas (e patológicas) criadas numa sociedade europeizada como a brasileira (Ramos, 1957: 194). Guerreiro Ramos aprofunda o debate ao fazer uma provocação de fundamento filosófico: o "niger sum", ou "negro sou":

Sou negro, identifico como meu o corpo em que o meu eu está inserido, atribuo à sua cor a suscetibilidade de ser valorizada esteticamente e considero a minha condição étnica como um dos suportes do meu orgulho pessoal - eis aí toda uma propedêutica sociológica, todo um ponto de partida para a elaboração de uma hermenêutica da situação do negro no Brasil (Ramos, 1957: 15. Grifos meus.).

Há nessa concepção de Guerreiro Ramos uma evidente evocação da máxima "Cogito ergo sum" ("Penso logo existo"), do filósofo René Descartes. Mas, sua preocupação é a seguinte: a modernidade me diz que se eu penso, logo eu existo. Mas, ainda que eu (corpo negro) pense, eu não existo para essa sociedade. O fundamento prático do "eu penso" é, de acordo com Enrique Dussel (1977), o "eu conquisto": "Penso, logo conquisto" (Dussel, 1977: 10). Ou seja, para conquistar é preciso antes de tudo ser. Na medida em que eu (corpo negro) não sou, não tenho existência para o outro, logo, estou passível de ser conquistado.

Todo esse debate nos lembra muito a discussão de Frantz Fanon (2008: 26) sobre o que ele chamou de "zona de não ser", que citamos no início deste texto. A existência para o outro, de acordo com Fanon, passa também pela possibilidade da fala: "Falar é existir absolutamente para o outro" (Fanon, 2008: 33). A suposição de que Guerreiro Ramos teria sido influenciado pelas ideias de Fanon ainda carece de investigação (Faustino, 2015). Mas, é possível encontrarmos semelhanças nas preocupações com a subjetividade do ser negro, como vimos no debate em torno da ideia de "niger sum" que, antes de tudo, passa pela problematização da experiência negra num contexto racializado.

A fala - condição mínima de convivência respeitosa numa sociedade - depende, antes de tudo, do reconhecimento do corpo enquanto legítimo. Por isso que, na luta contra o racismo, é muito importante compreendermos a força política da linguagem, do corpo e da estética, e aqui voltamos à bell hooks (1995). Na medida em que o corpo é negado, a própria existência com afirmação estética é um ato político, 
porque desestabiliza os discursos estabelecidos. Dito em outras palavras, a discussão sobre elementos culturais vernaculares de origem africana (estéticos, artísticos, refletidos na corporeidade) tem significado político.

A preocupação em não estabelecer uma cisão entre campo político e campo cultural está presente também em Joel Rufino dos Santos (1985: 300), ao atestar que essa distinção é, no mínimo, evolucionista e autoritária, na medida em que estabelece o "cultural" como desprovido de crítica e o "político" como lócus da ilustração, último estágio de amadurecimento intelectual. Ao afirmar o caráter político do cultural, Joel Rufino orienta os estudiosos da temática étnico-racial - e o próprio movimento negro - a estabelecer uma leitura da realidade brasileira com caráter supranacional, ou seja, liberta das ciladas impostas pelos limites nacionais (Santos, 1985: 301). Nesse sentido, considero o historiador e literato Joel Rufino dos Santos um autor fundamental para se realizar uma crítica construtiva para dentro da sociologia brasileira e das ciências sociais aqui realizadas.

Nesse mesmo sentido de crítica à dicotomia "cultura versus política", o intelectual Clóvis Moura critica o que Eric Hobsbawm chamou de "pré-político". Para Moura, o "descaso" com relação às manifestações culturais e às formas históricas de resistência negra, como o aquilombamento, é uma concepção elitista, eurocêntrica e que exclui os movimentos do Terceiro Mundo (Moura, 2000: 24). Ao propor o conceito de "Quilombagem", Clóvis Moura foca as ações de resistência movidas

5. Por exemplo, enquanto Clóvis Moura tinha forte atuação no Partido Comunista Brasileiro, realizando uma aproximação ao Movimento Negro apenas à partir na década de 1970, Guerreiro Ramos estava muito mais ligado ao Trabalhismo e ao legado Varguista, princípios que nortearam os intelectuais do Teatro Experimental do Negro, entre os quais Abdias do Nascimento. pela população negra na história do Brasil. Em Rebeliões da senzala, Clóvis Moura (1959) segue um percurso similar ao dos estudos de outros intelectuais marxistas, também negros, como Cyril Lionel Robert James (1934) em The black Jacobins e o próprio Frantz Fanon (1952) em Pele Negra, máscaras brancas. Moura descortinava na revolução violenta contra os racistas - e não apenas nas compensações subjetivas de uma identidade afro-centrada - uma forma de integração política do negro na sociedade ocidental.

Guardadas as devidas particularidades teóricas e políticas entre Clóvis Moura, Guerreiro Ramos e Joel Rufino dos Santos ${ }^{5}$, compreendo que cada um deles nos oferece leituras alternativas àquelas que tendiam a enclausurar o negro à situação de "objeto de estudo". Mais do que isso, são autores que nos possibilitam visualizar a agência do negro - entendida como ação, resistência e movimento - no contexto de um longo processo diaspórico que une Brasil e África. 


\section{Considerações finais}

O que busquei salientar com todo este debate é a existência de alguns pontos de toque entre a sociologia brasileira e as leituras críticas do processo colonial. E um elo importante para a compreensão desses pontos de toque é justamente as noções de ethos nacional e de modernidade. Os trabalhos pioneiros de Guerreiro Ramos, Roger Bastide, Clóvis Moura e Joel Rufino dos Santos, por exemplo, permitem-nos abrir os horizontes interpretativos sobre a história social do Brasil, na medida em que não limitam sua análise à nação, trazendo o tempo todo as conexões com o movimento da diáspora africana. Conferir um caráter transnacional à análise da história social do Brasil não significa apenas se reportar à história cruzada entre África, Brasil e a todo o contexto da diáspora africana, significa ainda realizar a crítica à fixação dos sujeitos realizada pelo discurso nacional. Afinal, há uma construção discursiva que nos constrange à posição de "brasileiros", quando, na verdade, somos tudo em nós mesmos, somos "viajantes" em significados, temos em nós muitas referências que nos impedem de nos fixarmos, a não ser provisoriamente. Aliás, o negro não é; tampouco o branco, porque, a única forma de materialização possível é no discurso (Fanon, 2008: 191).

Frente a tudo isso, o que significa "desracializar a experiência negra", tal como anunciado no título deste trabalho? Adoto os termos "racialização" e "experiência" nos sentidos dados por Frantz Fanon. Racialização - como já foi dito anteriormente - é o processo pelo qual uma série de significados desumanizadores são projetados sobre determinado grupo social, reduzindo-o a uma "zona de não ser", ou seja, a um lugar social de fragilidade ontológica, de sujeição. Essa é a experiência social vivenciada por negros da diáspora, dispersos pelo mundo e pelo Brasil, e que têm em comum a história da escravidão e os reflexos atuais (simbólicos, econômicos, políticos e culturais) do processo colonial. Eles também têm em comum uma longa história de resistências através de lutas diretas e também por outras estratégias políticas, como a estética e as artes.

Logo, um trabalho de revisão da sociologia brasileira na busca destes debates sobre a experiência de racialização nos faz emergir para fora do caudaloso discurso nacional homogeneizante. Esse discurso, absorvido e amplamente trabalhado pela sociologia brasileira, acabou por limitar a caracterização de negros a "descendentes de escravos" ou a eternos aspirantes à condição de sujeitos modernos na sociedade de classes. Eternamente aspirantes pois se caracterizariam antes como problema social, um desencaixe, ou ainda, enquanto seres distantes da desejada racionalidade. 
Revisitar alguns dos trabalhos da sociologia brasileira do ponto de vista da crítica colonial é uma oportunidade de se perceber elementos que inserem a história da população negra dentro de um processo colonial mais amplo que, se de um lado os desumanizou, por outro, e contraditoriamente, fez emergir infinitas formas de resistência e de ressignificação. Nesse sentido, e pelo menos do ponto de vista teórico, a releitura da sociologia brasileira buscando nela as caracterizações desse processo, nos coloca a possibilidade de encararmos outras narrativas, desracializadoras.

\section{Referências}

AVRITZER, Leonardo; GOMES, Lilian Cristina B. Política de reconhecimento, raça e democracia no Brasil. Dados, v. 56, n. 1, p. 39-68, 2013.

BASTIDE, Roger. As Américas Negras: as civilizações africanas no Novo Mundo. São Paulo: EdUSP, 1974.

BASTOS, Elide Rugai. As criaturas de Prometeu: Gilberto Freyre e a formação da sociedade brasileira. São Paulo: Global, 2006.

COHN, Gabriel. Padrões e dilemas: o pensamento de Florestan Fernandes. In: MORAES, R.; ANTUNES, R.; FERRANTE, V. L. B. (Orgs.). Inteligência brasileira. São Paulo: Brasiliense, 1986.

COSTA, Sérgio. Dois Atlânticos: teoria social, anti-racismo, cosmopolitismo. Belo Horizonte: Editora UFMG, 2006.

DELEUZE, Gilles; GUATTARI, Félix. Mil platôs - capitalismo e esquizofrenia. v. 1. Rio de janeiro: Editora 34, 1995.

DERRIDA, Jacques. Margins of philosophy. Chicago (IL): The University of Chicago Press, 1982.

DU BOIS, William Edward. B. As almas da gente negra. Rio de Janeiro: Lacerda editores, 1999.

DUSSEL, Enrique D. Filosofia da Libertação na América Latina. 2. ed. São Paulo: Loyola; Unimep, 1977.

FANON, Frantz. Os condenados da Terra. Juiz de Fora: Editora UFJF, 2010.

_. Pele negra, máscaras brancas. Salvador: EdUFBA, 2008. 
FAUSTINO, Deivison Mendes. Por que Fanon? Por que Agora? Frantz Fanon e os fanonismos no Brasil. Tese (Doutorado em Sociologia) - Programa de Pós-Graduação em Sociologia da Universidade Federal de São Carlos, São Carlos, São Paulo, 2015.

FERNANDES, Florestan. A integração do negro na sociedade de classes: o legado da raça branca, v. I e II. São Paulo: Editora Global, 5. ed., 2008.

FREYRE, Gilberto. Casa-Grande \& Senzala. Rio de Janeiro: Globo, 2006.

—. Interpretação do Brasil. Rio de Janeiro: José Olympio, 1947.

GILROY, Paul. O Atlântico Negro: modernidade e dupla consciência. São Paulo; Rio de Janeiro: Editora 34; Universidade Cândido Mendes/Centro de Estudos Afro-Asiáticos, 2001.

HALL, Stuart. Da diáspora. Identidades e mediações culturais. Belo Horizonte: Editora UFMG, 2006.

- Race, articulation, and societies structured in dominance. Sociological theories: race and colonialism. Paris: Unesco, 1980.

HOFBAUER, Andreas. Uma história de branqueamento ou o negro em questão. São Paulo: Editora Unesp, 2006.

HOLANDA, Sérgio Buarque de. Raízes do Brasil. São Paulo: Companhia das Letras, 2007.

HOOKS, bell. An aesthetic of blackness: strange and oppositional. Lenox Avenue: $A$ Journal of Inter-arts Inquiry, v. 1, p. 65-72, 1995.

HOROWITZ, Maryanne Cline. New dictionary of the history of ideas. New York: Charles Scribner's Sons, 2005.

MINTZ, Sidney W.; PRICE, Richard. O nascimento da cultura afro-americana: uma perspectiva antropológica. Rio de Janeiro: Pallas; Universidade Candido Mendes, 2003.

MOURA, Clóvis. Sociologia política da guerra camponesa de Canudos. São Paulo: Expressão Popular, 2003.

- Sociologia política da guerra camponesa de Canudos. São Paulo: Expressão Popular, 2000.

. Brasil: as raízes do protesto negro. São Paulo: Global Editora, 1983.

—. Rebeliões da senzala. São Paulo: Editora Zumbi, 1959. 
OSÓRIO, Rafael Guerreiro. Desigualdade racial e mobilidade social no Brasil: um balanço das teorias. In: THEODORO, Mário; SOARES, Sergei; JACCOUD, Luciana de Barros; OSÓRIO, Rafael Guerreiro (Orgs.). As políticas públicas e a desigualdade racial no Brasil: 120 anos após a abolição. Brasília: Ipea, 2008.

PORTELA JR., Aristeu. Democracia no Brasil: Florestan Fernandes e a transição. Áskesis - Revista dos Discentes do PPGS/UFSCar , v. 1, n. 2, p. 10-22, 2012.

RAMOS, Guerreiro. Introdução crítica à sociologia brasileira. Rio de Janeiro: Editorial Andes Ltda., 1957.

SALES JR., Ronaldo. Democracia racial: o não-dito racista. Tempo Social. Revista de Sociologia da USP, v. 18, n. 2, p. 229-258, 2016.

SANTOS, Joel Rufino dos. O movimento negro e a crise brasileira. Política e Administração, v. 2, Jul./Set. 1985.

SEGATO. Rita. The color-blind subject of myth; or, where to find Africa in the nation. Annu. Rev. Anthrop., v. 27, p. 129-151, 1998. 